\title{
Shaping Porous Materials for Hydrogen Storage Applications: A Review
}

\author{
Jianwei Ren* and Brian C. North
}

\begin{abstract}
HySA Infrastructure Centre of Competence, Materials Science and Manufacturing, Council for Scientific and Industrial Research (CSIR), PO Box 395, Pretoria 0001, South Africa
\end{abstract}

\begin{abstract}
Development of safe and effective hydrogen storage systems becomes a critical factor for further implementation of fuel cell and hydrogen technologies. Among new approaches aimed at improving the performance of such systems, the concept of porous materials-based adsorptive hydrogen storage is now considered as a long-term solution due to the reversibility, good kinetics and absence of thermal management issues. However, the low packing densities associated with the porous materials such as carbon structure materials, zeolites, metal-organic frameworks lead to the compromised volumetric capacity, potential pipe contaminations and difficulties in handling, when introducing the powdered adsorbents into hydrogen storage systems. Some efforts have been devoted to solve this problem by shaping the porous materials into beads, pellets or monoliths and achieve higher storage densities at more moderate temperatures and pressures.

This review will firstly state the essential properties of shaped structures for hydrogen adsorption, and then highlight the recent attributes that potentially can be utilized to shape porous materials into specific configurations for hydrogen storage applications. Later, several testing techniques on structured porous material will be also discussed.
\end{abstract}

Keywords: Porous materials, hydrogen storage systems, shaping process, application-specific configuration, packing density.

\section{INTRODUCTION}

Nowadays, it is critically important to develop the safe and effective hydrogen storage systems to ensure the further utilisation of hydrogen as fuel into fuel cell technologies. Hydrogen is a renewable fuel for providing future energy needs with a high gravimetric energy density of $120 \mathrm{~kJ} \cdot \mathrm{g}^{-1}$, and $4 \mathrm{~kg}$ hydrogen enable a typical car to travel about $400 \mathrm{~km}$ [1]. However, due to its very low volumetric energy density, such amount of hydrogen requires a tank with a volume of about 400 $L$ at a pressure of $15 \mathrm{MPa}$, and this volume can be only lowered down to $100 \mathrm{~L}$ at a pressure of $70 \mathrm{MPa}$ (Figure 1) [2]. Although hydrogen tanks with working pressures of $35 \mathrm{MPa}$ and $70 \mathrm{MPa}$ have been certified worldwide, tanks with such large volumes would make engineering work costly to safely store highly pressurized hydrogen. The safety concern of high pressures can be likely worked out by liquefaction with substantially reduced pressure, but it is not an economically option with the issues of liquefaction, engineered tank and hydrogen boil-off. Clearly, it remains stressful for the implementation of hydrogen as a competing fuel for its further utilisation without safe and effective techniques for its storage.

Materials-based adsorption storage, hydrogen gas as an adsorbed species within a suitable porous

*Address correspondence to this author at the HySA Infrastructure Centre of Competence, Materials Science and Manufacturing, Council for Scientific and Industrial Research (CSIR), PO Box 395, Pretoria 0001, South Africa;

Tel: +27 128412967; Fax: +27 128412135; E-mail: JRen@csir.co.za adsorbent [3-8], seems more efficient from reversibility, ease of fuelling and absence of thermal management issues, and is now considered as a long-term solution to meet stringent volumetric targets and offer lowpressure hydrogen storage [9]. Recent research efforts have demonstrated their ability to achieve higher storage capacities than that of traditional steel hydrogen cylinders (i.e. 1 wt.\% $\mathrm{H}_{2}$ ) $[10,11]$. However, the low packing densities associated with the porous materials such as carbon structure materials, zeolites, metal-organic frameworks (MOFs) result in the compromised volumetric capacity, potential pipe contamination and difficulties in handling, when the selected powdered adsorbents have to be introduced into a tank with pipe fittings. Some efforts have been made by Ford, BASF and University of Michigan to shape MOFs materials into application-specific configurations, and achieve higher storage densities at more moderate pressures to satisfy the driving range requirements [12-14]. For the shaped structures of porous materials as beads, pellets or monoliths, an appropriate mechanical strength is firstly essential to achieve low abrasion in packed beds. Secondly, a low flow resistance is expected to ensure a low-pressure drop. Thirdly, an intact or higher secondary surface area and pore volume is also desired for better hydrogen storage performance. Finally, the shaping process must be simple and cost effective.

With these in mind, this review will firstly state the essential properties of shaped structures for hydrogen 


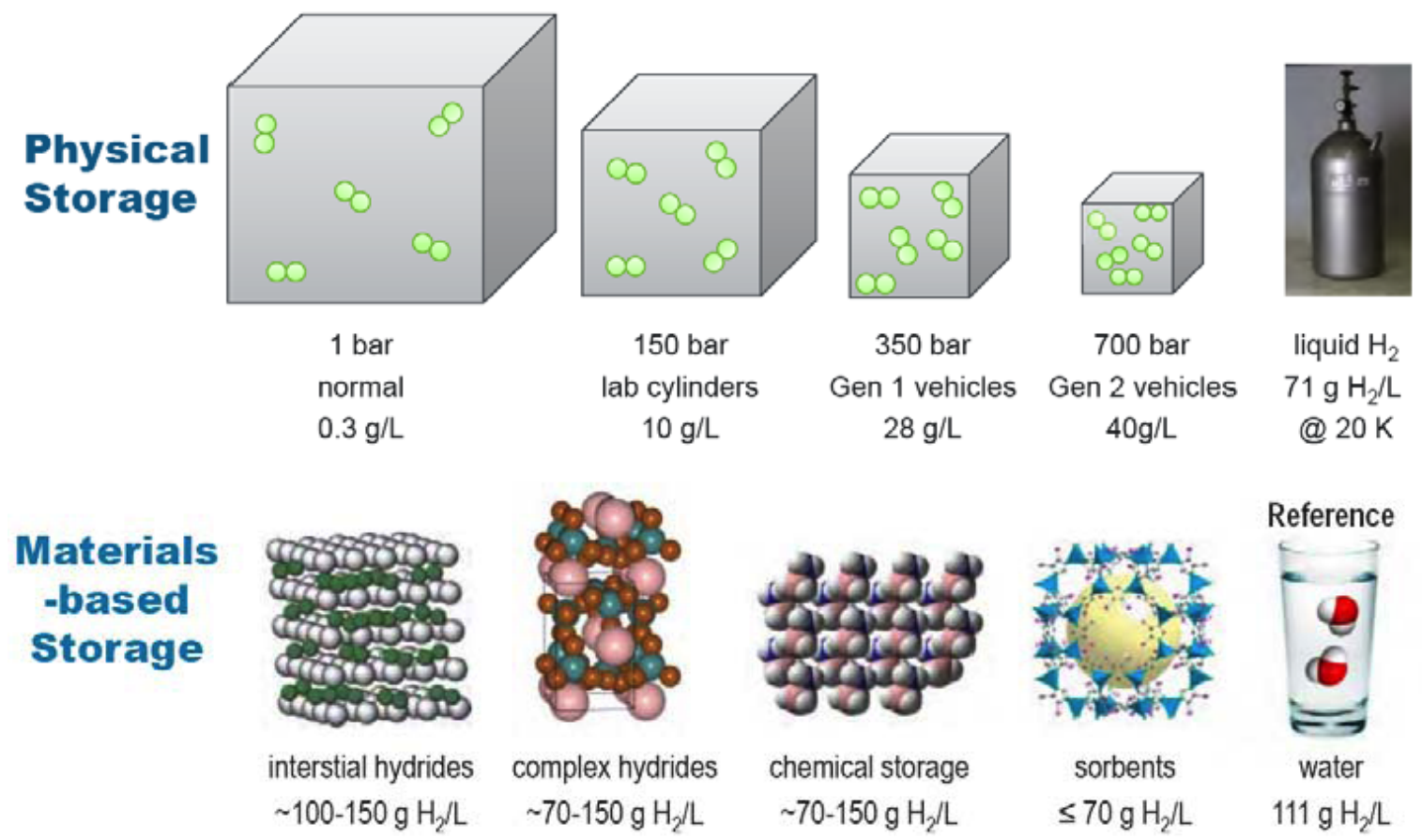

Figure 1: Compressed hydrogen vs. materials-based hydrogen storage [2]. Re-organized from Ref. [2], Copyright 2012.

absorption, and then highlight the recent attributes that potentially can be utilized to shape porous materials into specific configurations for hydrogen storage applications. Later, several testing techniques on the shaped structures are also discussed.

\section{ESSENTIAL PROPERTIES OF SHAPED STRUC- TURES}

For the integrated hydrogen storage systems to provide sufficient amount of hydrogen fuel for the target fuel cell system, the constraints are closely related to the properties of the packed materials, such as hydrogen storage capacity, mechanical property, thermal conductivity, hydrogen charge/discharge kinetics, cost, cycle life, and purity of released hydrogen [15-17]. The hydrogen storage capacity of shaped structures from a given porous material depends on their packing densities, secondary surface areas and pore volumes. It is recommended to optimize the shaping condition to balance the higher densities, secondary surface area and pore volume. Good mechanical property of the shaped structure is essential to resist abrasion and possible attrition from a real hydrogen storage practice, which depends firstly on the property of the given material itself, and secondly on the applied pressure or additives added during the shaping process. The kinetics of a materialsbased hydrogen supply system, from a practical standpoint, determine the rate at which the packed materials can supply hydrogen to the target fuel cell system to maintain a desired power load or conversely, the rate at which the packed materials can be refuelled [18]. The thermal conductivity of the shaped structures determines the design of the hydrogen storage system and its performance in applications. Given a shaped structure exhibits extremes of thermal conductivity behaviour and a heat exchanger will be needed within the storage vessel, the extra space and mass associated with this heat exchanger will inevitably lower the volumetric and gravimetric density of such hydrogen storage system. Thus, the sufficient thermal conductivity of the shaped structures would minimize the need for auxiliary thermal components and lead to improved system performance. Hydrogen charge/discharge kinetics on shaped structure relies on permeability and diffusivity of hydrogen gas into the shaped structure. Apart from the system's performance metric, cost is another crucial factor when evaluating the candidate storage technologies. Therefore, extensive use of expensive materials has to be avoided and cost-effective shaping process need to be verified. Although it is not always necessary to perform the cycling tests on the materials-based hydrogen storage systems at the early stage, it is important to identify any obvious degradation in capacity or kinetics of a given shaped structure at a fraction of the cycling target. The purity of the released hydrogen from the storage systems is critical for the performance of the fuel cell stacks, and necessary preliminary studies can provide information to guide materials selections [19]. 


\section{SHAPING TECHNIQUES}

Shaping techniques such as pressing, powder extrusion and template method are the ways to form powdered porous materials into complex shapes. The shaped structures with high mechanical stabilities offer to pack uniformly, maximize the bulk density, lessen wasted space in the storage vessel and resist attrition [20]. The selection of those shaping techniques however depends on the preparation methods and texture properties of the chosen porous materials.

\subsection{Mechanical or Hydraulic Pressing}

Mechanical or hydraulic pressing are widely selected for the shaping of dry powdered materials, but the production volumes of such method are normally low. Various bench top pellet presses provide a convenient and economical means for compressing powdered materials into pellet or tablet form without incurring the cost normally associated with expensive tablet making machinery. A pellet press is usually a stand-alone accessory with a lever arm, and different range of die sizes can be made from die sets. The produced pellets are cylindrical in shape with flat ends, certain height and thickness, depending upon the amount of material compressed and the force applied. The conventional pressing methods consist of mixing the active component with a selected binder, compression and moulding using a press and finally, pyrolysis to improve the binder properties and decrease the weight of binder in the pellets. The chosen binder helps to keep the active particles in a compressed state, and the shaped structures with enhanced properties are accessible with optimized shaping process. For the gas adsorption applications, the weight of the chosen binder should be added just enough to produce pellets with good mechanical properties, and meantime, its pyrolysis must not produce pore blocking of the powdered component. The chosen adsorbents in this regard include carbon [21-29] and MOFs porous materials [30], and the chosen binders cover humic acid-derived sodium salt [21], polyvinyl alcohol [21, 23,24,30], novolac phenolic resin [21], proprietary binder [21], Teflon [21] and adhesive cellulose-based binder [21]. polyvinyl pyrrolidone $[23,24]$, sodium derived carboxymethylcellulose sodium salt [23,24]. Polytetrafluorethylen [25,26], polyvinyl dichloride [27], phenolic resin [28]. The study from Lozano-Castelló et al. [21] showed that proprietary binder produced carbon monoliths with the best equilibrium between adsorption capacity and piece density, and no diffusion problems were presented for methane adsorption from kinetic study. The study on hydrogen storage capacity of a $1 \mathrm{~L}$ container filled with such monoliths was estimated to the $39.3 \mathrm{~g} \mathrm{H}_{2}$ at 4 $\mathrm{MPa}$ and $77 \mathrm{~K}$ [22]. Balathanigaimani et al. [23,24] proposed to consider the piece density for the effective design of the adsorption-based $\mathrm{H}_{2}$ gas storage system. Singer group [25] observed the detrimental effect of the PTFE polymer was greatest for large pores $(>1.5 \mathrm{~nm})$ and small particle sizes $(<1.5 \mathrm{~nm})$. The best-performing sample displayed excess and total volumetric capacities of 0.021 and $29 \mathrm{~g} \mathrm{H}_{2} \cdot \mathrm{L}^{-1}$, respectively, at 77 $\mathrm{K}$ and $4 \mathrm{MPa}$ hydrogen pressure. Kunowsky et al. [27] obtained a hydrogen adsorption capacity of $1 \mathrm{wt} . \%$ in its mechanically resistant monolith form at $298 \mathrm{~K}$. In the study of Biloe et al. [29], activated carbon was firstly coated with a thermoplastic binder and mixed with expanded natural graphite powder before being pressed into composite blocks. These composite blocks of $10-30 \%$ weight ratio of expanded natural graphite showed good methane adsorption capacities and good heat and mass transfer properties.

Although a binder can effectively increase the bulk density of powdered component, most of the binders used for this purpose reduce the adsorption performance of the powdered materials, since most of the commercial binders do not absorb gas and alternatively block the microporosity [30]. In some cases, activation can be conducted to re-develop the microporosity of the shaped structures [31], but this additional step is costly. Therefore, some efforts were made on carbonization [32], chemical activation $[33,34]$, hot-pressing [35-38] to verify the binder-less methods for shaping powder materials. Typically, the total surface area and pore volume will be decreased with the increased bulk densities of the shaped structures in compression pressure. Surprisingly, both the surface area and micropore volume were found increased from hot-pressing treatment, and the reduced average micropore size was also tunable by simply adjusting a pressure in the treatment. Obviously, a binder-less consolidated disc or monolithic structure without loss of micropore volume is preferred because it can be manufactured with higher bulk density and can be adapted to the shape of the container [39].

Joint research between Ford motor company, BASF and University of Michigan showed that higher densities of MOF- 5 materials can be achieved by mechanical compaction [40] without any binders, and thermal conductivity of MOF- 5 pellets can be enhanced with additive of expanded natural graphite powder [4145]. A $350 \%$ increase in volumetric $\mathrm{H}_{2}$ density was 
achieved on the pellet density of $0.5 \mathrm{~g} \cdot \mathrm{cm}^{-3}$ with only minor losses in gravimetric density. Other shaped MOFs structures such as MOF-177 monoliths [46,47], MIL-101 (Cr) monoliths [48,49], $\mathrm{Cu}_{3}(\mathrm{BTC})_{2}$ and UiO-66 pellets [50], CPO-27-Ni pellets [51,52] were also obtained by binder-less pressing and achieved enhanced volumetric hydrogen storage capacities. Interesting results from Peterson et al. [50] that the $\mathrm{Cu}_{3}(\mathrm{BTC})_{2}$ pressed materials showed reduced porosity, while the UiO-66 surface area remained consistent for all pressed samples.

\subsection{Powder Extrusion}

In a typical powder extrusion process, a suitable binder is firstly added into the active material to provide adequate plasticity for forming, and a rotating screw, together with heaters, heats the material and continuously pushes it through a die with the shape of the profile. After the die, the profile is cooled by air or water and cut into desired lengths. The production volumes of extrusion are normally much higher compared to the pressing method. Kim et al. [53] prepared $\mathrm{Cu}_{3}(\mathrm{BTC})_{2}$ pellets $\left(1 \mathrm{~cm}^{2}\right.$ width and $0.1 \mathrm{~cm}$ thickness) on a home-made extruder by using polyvinyl alcohol as a binder. The pellets showed lower catalytic properties than powder counterpart because of the increased pore diffusion resistance. Jasra et al. [54] indicated that the use of clay-type binders during pelletization of zeolites significantly affects the sorption and catalytic properties of the zeolite powder and mordenite. Küsgens et al. [55] extruded MOFs-based monoliths by using methyl hydroxyl propyl cellulose and methoxy functionalized siloxane ether as additive. The resulting monolithic $\mathrm{Cu}_{3}(\mathrm{BTC})_{2}$ structures have a specific surface area of $484 \mathrm{~m}^{2} \cdot \mathrm{g}^{-1}$ and showed a high mechanical stability of $320 \mathrm{~N}$.

\subsection{Template Techniques}

The applied templates in the template shaping techniques can be solids and emulsions. Solidtemplate are commonly used to form samples with desired shapes and ordered morphology. Silica monoliths [56,57], polymerized resorcinol [58-60], carbonized p-toluenesulfonic acid/glucose/resorcinol [61], ceramic titanium carbide [62], zeolite membrane [63] were used as templates from earlier work. The monolithic carbide-derived carbon synthesized by Yeon et al. [62] exhibited enhanced volumetric hydrogen storage capacity of $35 \mathrm{~g} \cdot \mathrm{L}^{-1}$, which was about $58 \%$ greater compared to powder equivalents at $25^{\circ} \mathrm{C}$ and 60 bar. Emulsion-templated technique, in general, involves forming a high internal phase emulsion and locking in the structure of the continuous phase, usually by reaction-induced phase separation such as sol-gol chemistry or free-radical polymerization. Subsequent removal of the internal phase (i.e. the emulsion droplets) gives rise to a porous replica of the emulsion [64]. O'Neill group [65] prepared a series of monodisperse mm-sized MOF spherical beads using an emulsion-templated oil/water/oil sedimentation polymerization technique. The resulting composites displayed hierarchical porosity with macro-/micro pores, and the degree of microporosity in the composites can be tuned by modulating the concentration of the reactants in the MOF synthesis. They also pointed out that any polymer scaffold with appropriate functionality, in principle, could be employed to prepare such materials with responsive functionality and enhanced properties over the individual MOFs components.

\section{TESTING TECHNIQUES ON SHAPED STRUC- TURES}

Apart from the testing techniques such as skeletal density, X-Ray diffraction patterns (XRD), Scanning electron microscope (SEM), Energy-dispersive X-ray spectroscopy (EDX), Fourier transform infrared (FTIR), thermo-gravimetric analysis (TGA), thermal conductivity, textural properties and hydrogen storage capacity, we here only discuss crush strength, drop test, tumbler test, permeability, diffusivity and $\mathrm{H}_{2}$ concentration.

\subsection{Crush Strength}

The crush strength is used to evaluate the performance of the shaped structures to resist abrasion and possible attrition from a real hydrogen storage practice. Purewal et al. $[42,43]$ tested the cylindrical MOF-5 pellets with flat ends on a mechanical testing system. The prepared pellets in certain dimensions were compressed on their side between two platen anvils at a rate of $0.5 \mathrm{~mm} \cdot \mathrm{min}^{-1}$ until mechanical failure, detectable as a drop in applied load and pellets broken. Küsgens et al. [55] measured the mechanical stability of $\mathrm{Cu}_{3}(\mathrm{BTC})_{2}$ monoliths using a Zwick 1455 (UIm, Germany) with a $1000 \mathrm{~N}$ force sensor at a test speed of $20 \mathrm{~mm} \cdot \mathrm{min}^{-1}$. The preliminary test force was set to 0.5 $\mathrm{N}$, and samples were cut in small pieces (dimensions: $3.5 \mathrm{~mm} \times 5 \mathrm{~mm} \times 8 \mathrm{~mm}$ ).

\subsection{Drop Test and Tumbler Test}

For those shaped structure presenting as spherical shapes, the degree of degradation is dependent on the 
severity of the handling treatment and the physical properties of the shaped pellets such as hardness, elasticity, cleavage and fracture, which differ not only from materials to materials, binders to binders, but also shaped sizes to sizes for the same material. The impact forces are the chief factor when the shaped pellets fall freely from different heights, or attrition occurs when hydrogen storage unit rolls, slides and vibrates. The degradation characteristics due to pellets breakage during handling can be evaluated by drop test, which is conducted in the vicinity of $0.5 \mathrm{~m}$ onto 10 $\mathrm{mm}$ thick steel plate [66]. The friability of shaped pellets can also be defined as the physical property of shaped pellets which express their tendency to be reduced in sized handling as a result of external forces such as impact and attrition $[67,68]$. Therefore, tumbler drum test, commonly used in the mineral field, can be used to estimate the friability of the shaped pellets due to attrition or abrasion during handling [69]. O'Neill et al. [65] mechanically stirred the MOF@PAM (PAM=macroporous poluacrylamide) beads for several hours in $\mathrm{EtOH}$ by means of a magnetic stirring flea, and the absence of breakage or MOF degradation allowed them to conclude that macroporous polymer scaffolds could stabilize bulk crystalline MOFs to mechanical attrition.

\subsection{Permeability, Diffusivity and $\mathrm{H}_{2}$ Concentration}

Porosity and permeability refer to geometrical property and physical property of a porous hydrogen storage material, respectively. More clearly, porosity is a measure of the gas/fluid storage capacity of a porous material, whereas permeability describes the conductivity of a porous material with respect to gas/fluid flow. Thus, permeability is related to the conectedness of the void spaces and the pore size of the porous medium, and can be calculated using a formula widely known as Darcy's law [70]:

$\mathrm{Q}=\frac{K . \Delta P \cdot A}{\mu \cdot \Delta x}$

Where

$\mathrm{Q}=$ the flowrate $\left(\mathrm{m}^{3} / \mathrm{s}\right)$;

$K=$ the permeability coefficient of the shaped pellet;

$\Delta P=$ the pressure drop across in the direction of the $\mathrm{H}_{2}$ flow;

$A=$ the cross sectional area of the shaped pellet $\left(\mathrm{m}^{2}\right)$;
$\Delta x=$ the flow length or thickness of testing sample in the direction of the $\mathrm{H}_{2}$ flow;

$\mu=$ th viscosity of $\mathrm{H}_{2}$ gas (Pa.s).

For each experimental point, the hydrogen viscosity can be referred to Gas Viscosity Calculator [71], where the viscosity of hydrogen at different temperatures can be calculated using Sutherland's formula [72]:

$\mu=\mu_{0}^{*}(a / b)^{*}\left(T / T_{0}\right)^{3 / 2}$

$a=0.555 T_{0}+C$

$b=0.555 T+C$

Where

$\mu=$ viscosity in centipoise at input temperature $\mathrm{T}$;

$\mu_{0}^{*}=$ reference viscosity in centipoise at reference temperature $T_{o}$;

$T$ =input temperature in degree Rankine;

$T_{0}=$ reference temperature in degrees Rankine;

$C=$ Sutherland's constant

The permeability coeffieient $K$ depends on the combination of the gas and porous material used. The greater the value of $K$, the higher will be the flow rate of a gas through a material. The permeability coeffieient can be used for ranking porous media in gas adsorption and speading rate and for estimation of pore size [73-76].

In the work of $\mathrm{Xu}$ et al. [45], a setup for $\mathrm{H}_{2}$ permeability measurement was built as shown in Figure 2. The tested pellet was secured in the sample holder using silicone adhesive sealant sealing around the sample edge. The effective gas flow diameter $d$ was $1.00 \mathrm{~cm}$, and the sample thickness $h$ was $0.5 \mathrm{~cm}$ (Figure 2b). The pressure drop was calculated from the upstream and downstream pressures, measured by two pressure transducers $P_{1}$ and $P_{2}$, respectively. The temperature of the sample was recorded by a thermocouple positioned downstream about $5 \mathrm{~mm}$ near the sample. All the measurement was based on computer equipped with a data acquisition module. A liquid $\mathrm{N}_{2}$ Dewar was used for the cryogenic $\mathrm{H}_{2}$ transport measurements at $77 \mathrm{~K}$ (see Figure 2a). The negative thermal-expansion coefficient of shaped MOF5 structure helped to secure the seal between the sample and the sample holder $[77,78]$. 


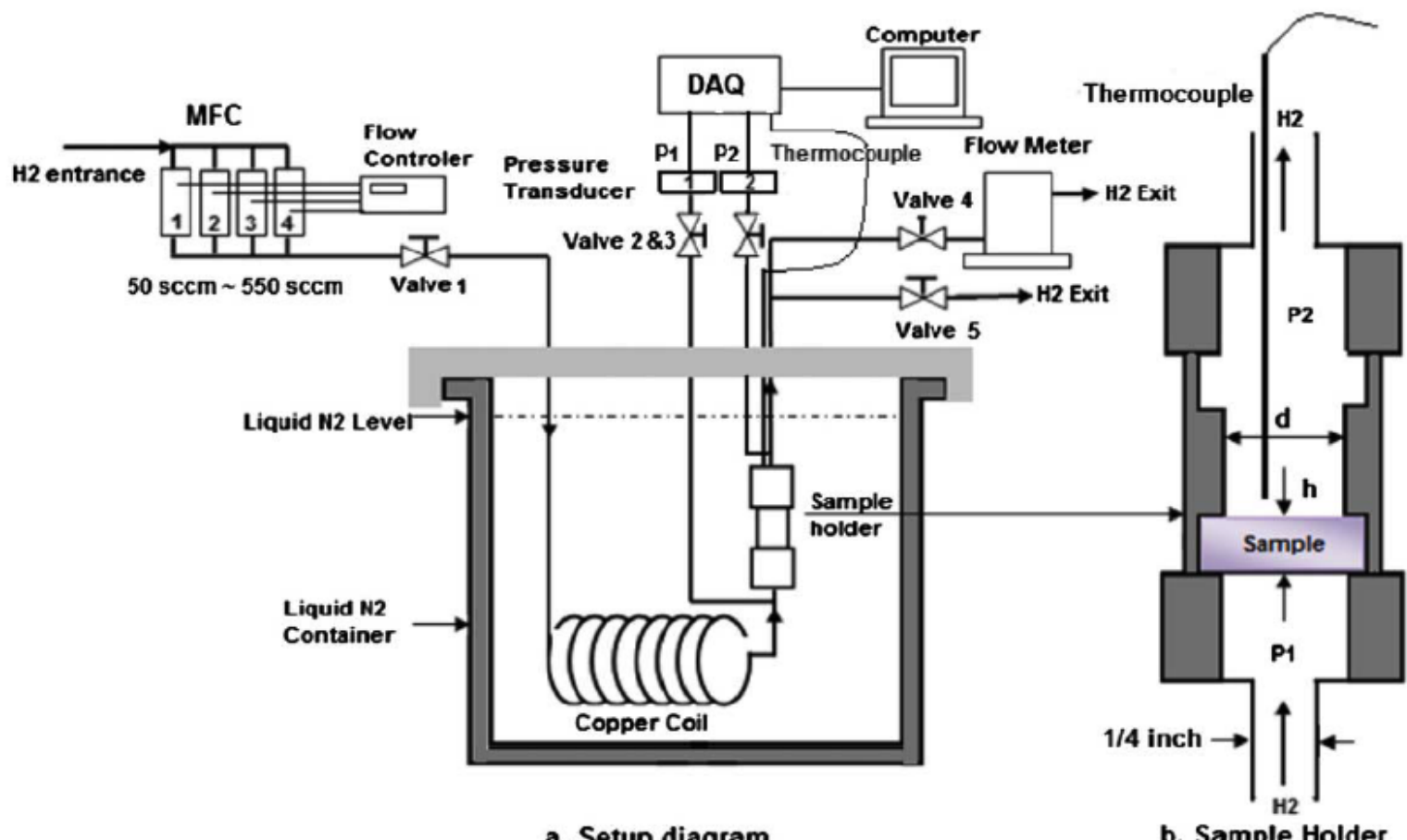

Figure 2: Diagram of the $\mathrm{H}_{2}$ permeability measurement apparatus [45]. Reprinted from Ref. [45], Copyright 2013, with permission from Elsevier.

The $\mathrm{H}_{2}$ diffusivity in shaped structure under steady flow conditions was calculated based on the measured pressure drop at each flow fate and one dimension (1D) Fick's first law:

$$
D_{\mathrm{f}}=\frac{J R T h}{\Delta P}
$$

Where

$D_{f}=$ the Fick's diffusivity or diffusion coefficient $\left(\mathrm{m}^{2} \cdot \mathrm{s}^{-1}\right)$;

$J=$ the gas mole flux per square meter at steady flow state $\left(\mathrm{mol} \cdot \mathrm{m}^{2} \cdot \mathrm{s}^{-1}\right)$;

$R=$ the ideal gas constant $8.3145 \mathrm{~J} \cdot \mathrm{mol}^{-1} \cdot \mathrm{K}^{-1}$;

$T=$ gas temperature $(\mathrm{K})$;

$h=$ the sample thickness $(\mathrm{m})$;

$\Delta P=$ the pressure drop.

Subsequently, the $\mathrm{H}_{2}$ concentration in the sample was derived using Fick's second law:

$\frac{\partial C}{\partial t}=D_{f} \frac{\partial^{2} C}{\partial \chi^{2}}$

At time $t=0$, the initial upstream and the downstream background $\mathrm{H}_{2}$ concentration are constant
$C_{1}$ and $C_{2}$, respectively. For $\mathrm{H}_{2}$ diffusion in a 1-D half infinite length sample, $\mathrm{H}_{2}$ concentration at position $\chi$ $(\mathrm{cm})$ away from the upstream surface and time $t$ can be expressed as:

$$
C(t, \chi)=C_{1}-\left(C_{1}-C_{2}\right) \operatorname{erf}\left(\frac{\chi}{2 \sqrt{D_{f} t}}\right)
$$

\section{CONCLUSIONS}

Hydrogen energy is one of the renewable fuels for providing future energy needs without harming the environment. However, hydrogen has a very low volumetric energy density, and the development of the effective systems to store hydrogen is a key factor for its further utilisation. Among the storage options, porous materials-based adsorptive hydrogen storage systems have proved their capabilities to achieve higher storage capacities than that of traditional steel hydrogen cylinders at lower pressures. Equally important with the discovery of various porous materials for hydrogen storage, the integration of those given materials into a hydrogen storage system remains another engineering challenge. The porous materials obtained from conventional synthesis methods are normally loose powders with low packing densities, which lead to the low volumetric capacity, potential pipe contaminations and difficulties in 
handling. Therefore, the shaped structures such as beads, pellets or monoliths are expected instead of the powdered porous materials.

Several techniques such as pressing, powder extrusion and template methods have been used to form the chosen porous materials into complex shapes. Among these shaping techniques, the production volume from extrusion is normally higher than the other two, but pressing method provides a convenient and economical means for shaping powdered materials into structures without incurring the cost associated with expensive machinery. The shaped structures are expected to offer high mechanical stability, low moisture sensitivity, high packing density, and high hydrogen storage capacity. A proper binder helps to increase the bulk density of the powdered material, however, most of the binders used for this purpose reduce the adsorption performance of the active storage materials, since they do not adsorb hydrogen and alternatively block the microporosity. In certain cases, activation can be applied to re-develop the microporosity of the shaped structure, but this additional step is costly. For the gas adsorption applications, the weight of the chosen binder should be added just enough to produce shaped structure with good mechanical properties, and the later pyrolysis must not produce pore blocking of the active component. Some binder-less methods have been developed to minimize the loss of total surface area and pore volume from pores blockage. Interestingly, both the surface area and micropore volume increase from hot-pressing treatment, and the reduced average micropore size can also be tuned by simply adjusting the pressure in the treatment.

For the shaped structures, an appropriate mechanical strength is firstly essential to achieve low abrasion in packed beds. Secondly, a low flow resistance is expected to ensure a low-pressure drop. Thirdly, an intact or higher secondary surface area and pore volume is also desired for hydrogen adsorption. Finally, the production process must be simple and cost effective. Some preliminary information can be obtained on crush strength, drop test, tumbler test, permeability and diffusivity to guide the materials and processes selection.

\section{ACKNOWLEDGEMENTS}

The author would like to thank financial support of the South African Department of Science and Technology (DST). The content and opinions expressed in this paper are specifically those of the author's and do not necessarily reflect the position or policy of the South African government.

\section{REFERENCES}

[1] Germain J, Fréchet JMJ, Svec F. Small 2009; 5: 1098-111. http://dx.doi.org/10.1002/smll.200801762

[2] Stetson N. An overview of U.S. DOE's activities for hydrogen fuel cell technologies, 2/27/2012, Clearwater, Floride, America.

[3] Orimo S, Züttel A, Schlappbach L, Majer G, Fukunaga T, Fujii H. J Alloys Compd 2003; 356-357: 716-9. http://dx.doi.org/10.1016/S0925-8388(03)00175-0

[4] Buczek B, Czepirski L, Zietkiewicz J. Adsorption 2005; 11: 877-80. http://dx.doi.org/10.1007/s10450-005-6039-8

[5] Shi SZ, Hwang JY, Li X, Sun X, Lee BI. Int J Hydrogen Energy 2010; 35: 629-31. http://dx.doi.org/10.1016/j.ijhydene.2009.11.008

[6] Azzouz A. Int J Hydrogen Energy 2012; 37: 5032-49. http://dx.doi.org/10.1016/j.ijhydene.2011.12.024

[7] Schlichtenmayer M, Streppel B, Hirscher M. Int J Hydrogen Energy 2011; 36: 586-91. http://dx.doi.org/10.1016/j.ijhydene.2010.09.057

[8] Pedicini R, Saccà, Carbone A, Passalacqua E. Int J Hydrogen Energy 2011; 36: 9062-8. http://dx.doi.org/10.1016/j.ijhydene.2011.04.176

[9] Nechaev YS, Alexeeva OK. Int J Hydrogen Energy 2003; 28 : 1433-43.

http://dx.doi.org/10.1016/S0360-3199(03)00004-1

[10] Satyapal S, Petrovic J, Read C, Thomas G, Ordaz G. The U.S. Catal Totay 2007; 120: 246-56. http://dx.doi.org/10.1016/j.cattod.2006.09.022

[11] Materials-based hydrogen storage [homepage on the Internet]. Available from: http://www1.eere. enery.gov/hydrogenandfuelcells/storage/current_technology.html.

[12] Marco-Lozar JP, Juan-Juan J, Suárez-García F, CazorlaAmorós D, Linares-Solano A. Int J Hydrogen Energy 2012; 37: 2370-81.

http://dx.doi.org/10.1016/j.ijhydene.2011.11.023

[13] Kunowsky M, Marco-Lozar JP, Cazorla-Amorós D, LinaresSolano A. Int J Hydrogen Energy 2010; 35: 2393-402. http://dx.doi.org/10.1016/j.ijhydene.2009.12.151

[14] U.S. Department of Energy, Targets for on-board hydrogen storage systems: Current R\&D focus is on 2015 targets with potential to meet ultimate targets. Available from: Http://www1.eere.energy.gov/hydrogenandfuelcells/ pdfs/freesomcar_targets_explanations.pdf.

[15] McWhorter S, Read C, Ordaz G, Stetson N. Curr Opin Solid St M Sci 2011; 15: 29-38. http://dx.doi.org/10.1016/j.cossms.2011.02.001

[16] Yang J, Sudik A, Wolverton C, Siegel DJ. Chem Soc Rev 2010; 39: 656-75. http://dx.doi.org/10.1039/b802882f

[17] Gross KJ, Carrington KR. Recommended best practice for the characterization of storage properties of hydrogen storage materials. http://www1.eere.energy.gov/hydrogenandfuelcells/pdfs/best_practices_hydrogen_storage.pdf.

[18] Technical system targets: onboard hydrogen storage for light-duty fuel cell vehicles. Available from: http://www1. eere.energy.gov/hydrogenandfuelcells/storage/pdfs/targets_ onboard_hydro_storage.pdf.

[19] Bernauer O, Topler J, Noreus D, Hempelmann R, Richter D. Int J Hydrogen Energy 1989: 14:187-200. http://dx.doi.org/10.1016/0360-3199(89)90053-0 
[20] Quinn DF, MacDonald JA. Carbon 1992; 30(7): 1097-103. http://dx.doi.org/10.1016/0008-6223(92)90141-I

[21] Lozano-Castelló D, Cazorla-Amorós D, Linares-Solano A, Quinn DF. Carbon 2002; 40(15): 2817-25. http://dx.doi.org/10.1016/S0008-6223(02)00194-X

[22] Jordá-Beneyto $M$, Lozano-Castelló $D$, Suárez-Garcĺa $F$, Cazorla-Amorós D, Linares-Solano Á. Micro Meso Mater 2008; 112: 235-42.

http://dx.doi.org/10.1016/j.micromeso.2007.09.034

[23] Balathanigaimani MS, Shim WG, Lee JW, Moon H. Micro Meso Mater 2009; 119: 47-52.

http://dx.doi.org/10.1016/j.micromeso.2008.09.034

[24] Balathanigaimani MS, Shim WG, Kim TH, Cho SJ, Lee JW, Moon H. Catal Today 2009; 146: 234-40. http://dx.doi.org/10.1016/j.cattod.2009.02.025

[25] Singer JP, Mayergoyz A, Portet C, Schneider E, Gogotsi Y, Fischer JE. Micro Meso Mater 2008; 116: 469-72. http://dx.doi.org/10.1016/j.micromeso.2008.05.005

[26] Chmiola J, Yushin G, Gogotsi Y, Portet C, Simon P, Taberna PL. Science 2006; 313: 1760-3. http://dx.doi.org/10.1126/science.1132195

[27] Kunowsky M, Marco-Lozar JP, Oya A, Linares-Solano A. Carbon 2012; 50: 1407-16. http://dx.doi.org/10.1016/j.carbon.2011.11.013

[28] Sun J, Brady TA, Rood MJ, Lehmann CM. Energ Fuel 1997; 11: 316-22.

http://dx.doi.org/10.1021/ef960201h

[29] Biloe S, Goetz V, Mauran S. Carbon 2001; 39: 1653-62. http://dx.doi.org/10.1016/S0008-6223(00)00288-8

[30] Finsy V, Ma L, Alaerts L, De Vos DE, Baron GV, Denayer JFM. Micro Meso Mater 2009; 120: 221-7. http://dx.doi.org/10.1016/j.micromeso.2008.11.007

[31] Muto A, Bhaskar T, Tsuneishi S, Sakata Y, Ogasa H. Energ Fuel 2005; 19: 251-7. http://dx.doi.org/10.1021/ef0400316

[32] Inomata K, Urabe KY, Hosono H, Araki T. Carbon 2002; 40: 87-93. http://dx.doi.org/10.1016/S0008-6223(01)00084-7

[33] Garcla Blanco AA, Alexandre de Oliveira JC, López R, Moreno-Piraján JC. Collod Surface A: Physicochem Eng Aspects 2010; 357: 74-83.

[34] Nakagawa Y, Molina-Sabio M, Rodriuez-Reinoso F. Micro Meso Mater 2007; 103: 29-34. http://dx.doi.org/10.1016/j.micromeso.2007.01.029

[35] Hou PX, Orikasa H, Itoi H, Nishihara H, Kyotani T. Carbon 2007; 45: 2011-6.

http://dx.doi.org/10.1016/j.carbon.2007.05.029

[36] Celzard A, Albiniak A, Jasienko-Halat M, Marêché JJ. Furdin G. Carbon 2005; 43: 1990-9. http://dx.doi.org/10.1016/j.carbon.2005.03.022

[37] Bekyarova E, Murata K, Yudasaka M, Kasuya D, lijima S, Tanaka H, Kahoh H, Kaneko K. J Phys Chem B 2003; 107: 4681-8. http://dx.doi.org/10.1021/jp0278263

[38] Guan C, Loo LS, Wang K, Yang C. Energy Convers Manage 2011; 52: 1258-62.

http://dx.doi.org/10.1016/j.enconman.2010.09.022

[39] Biloé S, Goetz V, Mauran S. Carbon 2001; 39: 1653-62. http://dx.doi.org/10.1016/S0008-6223(00)00288-8

[40] Hesse M, Mueller U, Yaghi OM, inventor. Shaped bodies containing metal-organic frameworks. United States Patent US7524444 B2, 2009Apr.

[41] Liu D, Purewal JJ, Yang J, Sudik A, Maurer S, Mueller U, Ni J, Siegel DJ. Int J Hydrogen Energy 2012; 37: 6109-17. http://dx.doi.org/10.1016/j.ijhydene.2011.12.129
[42] Purewal J, Liu D, Sudik A, Veenstra M, Yang J, Maurer S, Müller U, Siegel DJ. J Phys Chem C 2012; 116: 20199-212. http://dx.doi.org/10.1021/jp305524f

[43] Purewal JJ, Liu D, Yang J, Sudik A, Siegel DJ, Maurer S, Müller U. Int J Hydrogen Energy 2012; 37: 2723-7. http://dx.doi.org/10.1016/j.ijhydene.2011.03.002

[44] Hu YH, Zhang L. Physil Rev B 2010; 81: 174103-7. http://dx.doi.org/10.1103/PhysRevB.81.174103

[45] Xu C, Yang J, Veenstra M, Sudik A, Purewal JJ, Ming Y, Bardy BJ, Warner J, Maurer S, Müeller U, Siegel DJ. Int J Hydrogen Energy 2013; 38: 3268-74.

http://dx.doi.org/10.1016/j.ijhydene.2012.12.096

[46] Zacharia R, Cossement D, Lafi L, Chahine R. J Mater Chem 2010; 20: 2145-51. http://dx.doi.org/10.1039/b922991d

[47] Dailly A, Poirier E. Energy Environ Sci 2011; 4: 3527-34.

[48] Ardelean O, Blanita G, Borodi G, Lazar MD, Misan I, Coldea I, Lupu D. Int J Hydrogen Energy 2013; 38: 7046-55. http://dx.doi.org/10.1016/j.ijhydene.2013.03.161

[49] Oh H, Blanita G, Lupu D, Hirscher M. RSC Adv 2014; 4: 2648-51.

http://dx.doi.org/10.1039/c3ra46233a

[50] Peterson GW, DeCoste JB, Glover TG, Huang YG, JasujaH, Walton KS. Micro Meso Mater 2013; 179: 48-53. http://dx.doi.org/10.1016/j.micromeso.2013.02.025

[51] Tagliabur M, Rizzo C, Millini R, Dietzel PDC, Blom R, Zanardi S. J Porous Mater 2011; 18: 289-96. http://dx.doi.org/10.1007/s10934-010-9378-0

[52] Liu J, Tian J, Thallapally PK, McGrail BP. J Phys Chem C 2012; 116: 9575-81.

http://dx.doi.org/10.1021/jp300961j

[53] Kim J, Kim SH, Yang ST, Ahn WS. Micro Meso Mater 2012; 161: 48-55.

http://dx.doi.org/10.1016/j.micromeso.2012.05.021

[54] Jasra RV, Tyagi B, Badheka YM, Choudary VN, Bhat TSG. Ind Eng Chem Res 2003; 42: 3263-72.

http://dx.doi.org/10.1021/ie010953/

[55] Küsgens P, Zgaverdea A, Fritz HG, Siegle S, Kaskel S. J Am Ceram Soc 2010; 93: 2476-9.

http://dx.doi.org/10.1111/j.1551-2916.2010.03824.x

[56] Fan LZ, Hu YS, Maier J, Adelhelm P, Smarsly B, Antonietti M. Adv Funct Mater 2007; 17(16): 3083-7. http://dx.doi.org/10.1002/adfm.200700518

[57] Taguchi A, Smått JH, Lindén M. Adv Mater 2003; 15: 120911. http://dx.doi.org/10.1002/adma.200304848

[58] Kabbour H, Baumann TF, Satcher Jr. JH, Saulnier A, Ahn CC. Chem Mater 2006; 18(26): 6085-7. http://dx.doi.org/10.1021/cm062329a

[59] Baumann TF, Worsley MA, Han YJ, Satcher Jr. JH. J. NonCrystalline Solids 2008; 354: 3513-5. http://dx.doi.org/10.1016/j.jnoncrysol.2008.03.006

[60] Li WC, Lu AH, Schüth F. Chem Mater 2005; 17: 3620-6. http://dx.doi.org/10.1021/cm050345m

[61] Zhang WL, Tao HX, Zhang BH, Ren JW, Lu GZ, Wang YQ. Carbon 2011; 49: 1811-20. http://dx.doi.org/10.1016/j.carbon.2010.12.050

[62] Yeon SH, Knoke I, Gogotsi Y, Fischer JE. Micro Meso Mater 2010; 131: 423-8. http://dx.doi.org/10.1016/j.micromeso.2010.02.002

[63] Lachawiec Jr. A, Qi G, Yang RT. Langmuir 2005; 21(24): 11418-24 http://dx.doi.org/10.1021/la051659r

[64] Zhang H, Copper Al. Chem Mater 2002; 14: 4017-20. http://dx.doi.org/10.1021/cm0206643 
[65] O'Neill LD, Zhang HF, Bradshaw D. J Mater Chem 2010; 20: 5720-6. http://dx.doi.org/10.1039/c0jm00515k

[66] Kawatra SK, Ripke SJ. Int J Miner Process 2002; 65(3-4): 141-9.

http://dx.doi.org/10.1016/S0301-7516(01)00062-X

[67] Vogel JC, Quass FW. J Chem Metal Min Soc S Af, Part-I 1937; 469-78.

[68] Yancy HF, Zane RE. Comparison of methods for determining the friability of coal, U.S. Bureau of Mines report of Investigations vol. 3215, 1933: 1-24.

[69] Sahoo R. Powder Technol 2007; 176: 77-87. http://dx.doi.org/10.1016/j.powtec.2007.02.013

[70] Pal L, Joyce MK, Fleming PD. Tappl J 2006; 5: 10-6.

[71] Flow gas viscosity [homepage on the Internet]. Available from: http:// www.Imnoeng.com/Flow/GasViscosity.htm
[72] Crane Company. Flow of fluids through valves, fittings, and pipe. Technical Paper No. 410 (TP 410), 1988.

[73] Mokadam RG. J Appl Mech 1961; 28: 208-12. http://dx.doi.org/10.1115/1.3641653

[74] Carson FT. Bur Standards J Res 1934; 12: 587-608. http://dx.doi.org/10.6028/jres.012.055

[75] Jr. Bublitz WJ. A study of the air permeability of paper at high pressures. Mater's thesis, Appleton, Wis., The Institute of Paper Chemistry, 1947; p. 89-90.

[76] Coupe RR. Proc Tech Sect British Paper \& Board Makers' Assoc. 31, 1950; 2: 383-457.

[77] Zhou W, Wu H, Yildirim T, Simpson JR, High Walker AR. Phys Rev B 2008; 78: 054114: 1-5.

[78] Lock N, Wu Y, Christensen M, Cameron LJ, Peterson VK, Bridgeman AJ, Kepert CJ, Iversen BB. J Phy Chem C 2010; 114: 16181-6.

http://dx.doi.org/10.1021/jp103212z 